\title{
LA GEOGRAFÍA HOY: REFLEXIONES SOBRE EL PENSAMIENTO GEOGRÁFICO, LA REGIÓN Y LA DOCENCIA DE LA GEOGRAFÍA
}

\author{
Jorge Olcina Cantos
}

«La formación del geógrafo debería prestar atención a la historia del pensamiento geográfico, a las ideas que han modulado y orientado la investigación geográfica y a los medios intelectuales circundantes en los que ha vivido la geografía en diferentes épocas y lugares».

Carl O. Sauer, La educación de un geógrafo, 1956.

\section{RESUMEN}

Resulta esencial, en cualquier disciplina, el conocimiento de las bases de pensamiento sobre las que se debe asentar cualquier reflexión futura de teoría y método de la misma. Cuestión distinta es aceptar, sin más, las ideas expresadas en su día por los maestros de la disciplina y, aún peor, no aventurarse a llevar a cabo propuestas de mejora de la ciencia por la que se ha apostado como futuro profesional. Se presentan aquí unas reflexiones personales sobre el pensamiento geográfico, sobre la región y las nuevas corrientes que para ella se presumen y sobre la docencia de la geografía con especial referencia al actual proceso de renovación de las enseñanzas geográficas.

Palabras clave: Pensamiento geográfico, región, docencia de la geografía, planes de estudio, geografía aplicada.

\section{ABSTRACT}

To have a thorough of knowledge of the bais of thought on which we must lay our future reflection about theory and method results essential in some subject. Another question is to accept, without more ado, ideas express, in due time, for the masters of the subject and, too bad, to avoid preparing some propositions in order to improve the science an which one have staked for his future profession. In this paper, we show some reflections on the geographical thought, on the region and his new trends and on the geographical teaching. We make special reference to the recent changes taked place in the last one.

Key words: Geographical thought, region, geographical teaching, new teaching programmes, practical geography. 
Resulta común encontrar en la bibliografía geográfica española artículos y libros que versan sobre el pensamiento geográfico, y aún, regional, editados con posterioridad a procesos de concurso de acceso a cuerpos de docencia universitaria, que contienen muchas de las ideas vertidas en el proyecto docente. Es ésta una finalidad loable, mediante la cual el autor intenta participar, al resto de la comunidad geográfica, las opiniones y reflexiones a las que ha llegado tras meses de sesudas lecturas y aproximaciones a la obra y pensamiento de los maestros de la disciplina. Se editan, de este modo, capítulos enteros de los proyectos docentes o, si la extensión lo impide, resúmenes de los mismos en los que se intenta plasmar la madurez de pensamiento alcanzada por el autor a lo largo de su trayectoria universitaria.

Con ser esto esencialmente necesario para el progreso de una ciencia, pocas veces las páginas publicadas contienen inquietudes verdaderamente personales, ideas propias sobre la disciplina a la que el autor ha orientado su futuro profesional. Los escritos editados se convierten, las más de las veces, en meras copias de pensamientos que otros han reflexionado con anterioridad y han plasmado en obras primeras. Frases como «...en opinión de Ritter...», «...como señala Vidal de la Blache...», «...como afirma Bunge...», salpican los escritos, en un intento, sin duda necesario, por demostrar que se conocen las ideas de los distintos autores protagonistas del pensamiento geográfico. No faltan transcripciones literales de los clásicos, que alcanzan punto máximo de pedantería cuando se reproducen en su idioma original, sin incluir traducción a la lengua de Cervantes, en un intento - no bien intencionado - de poner en evidencia al lector que, por circunstancias, puede estar poco avezado en idiomas extranjeros, o, tal vez, como medio de ocultar la poca destreza frente a la lengua bárbara a la hora de transcribir literalmente dichas reflexiones.

El problema surge cuando la redacción de estas obras se limita a ello, convirtiéndose en meras copias, carentes de valoración personal, de las propuestas formuladas por estos autores, siguiendo la consigna del relato refero. Y lo peor es cuando los trabajos concluyen con frases, tan manidas, como «...pienso, como dice ..., », ante las cuales, uno estima sí ha sido útil el esfuerzo realizado por interpretar la reflexión de la disciplina que se practica, sí la labor personal de aproximación al pensamiento geográfico sirve al colectivo de geógrafos para aclarar ideas poco conocidas o comprendidas, o sí, por contra, hubiera sido mejor dedicar este esfuerzo a otros asuntos ante la evidencia de que la conclusión a la que se llega es, únicamente, apoyar lo que otros han pensado anteriormente. Cabe, en estos casos, el examen de conciencia personal de valorar sí se merece el puesto que se va a ocupar en la docencia universitaria.

Estimo, en estos casos, que la labor de mostrar las ideas contenidas en la evolución del pensamiento geográfico debe estar plagada de opiniones personales, de provocación meditada, en suma, de actitud ilusionante ante la difícil misión de presentar las bases de reflexión de la ciencia por la que se ha apostado como actitud de vida. A ello debe aspirar el geógrafo preocupado por las cuestiones de epistemología y de su enseñanza a las jóvenes generaciones.

Sirva este proemio para ilustrar las páginas que se presentan, que sólo quieren ser una apuesta personal en la manera de entender la tradición geográfica, la actitud que debe adoptar el geógrafo ante esta tradición y la apasionante labor de presentar estas ideas ante la sociedad — docencia — en el momento actual.

\section{A. Sobre el pensamiento geográfico}

Toda disciplina de conocimiento intenta siempre adquirir el rango de ciencia para ocupar un lugar superior en la estructura de pensamiento. La ciencia se ocupa de la búsqueda de la 
verdad, pero ésta resulta ser siempre una idea abstracta. Toda ciencia es una invención de la mente humana que, una vez creada, adopta la condición de verdad absoluta. Esto significa que necesitamos comprender la naturaleza de la verdad y el método de llegar a ella.

Si una cuestión ha preocupado sobremanera, al menos desde el s. XIX, en el pensamiento geográfico, ésta ha sido la posibilidad de incluir a la geografía en el universo de las ciencias, es decir, tener la seguridad y la plena convicción de que la geografía es una ciencia. Existen múltiples acepciones del término «ciencia»; sin duda, los primeros recuerdos de los años de escuela nos proporcionan rápidamente algunas de ellas: como indica Unwin (1995) se suele asociar la ciencia con aquello que se estudia en los laboratorios y precisa instrumentos. La ciencia está formada, bajo este prisma estudiantil, por asignaturas como física, química, biología por oposición a las asignaturas artísticas o humanísticas, como el arte o la lengua y literatura, que son menos precisas y están más relacionadas con la imaginación y la creatividad. La ciencia se encarga de proporcionar teorías generales que explican fenómenos concretos. En este modelo, las ciencias y las artes se diferencian tanto por el objeto de estudio como por los métodos que utilizan. La geografía, por interesarse tanto por el mundo físico como por el humano, nunca se ha considerado como miembro de pleno derecho de ninguna de las dos categorías anteriores. En el sistema educativo anglosajón, por ejemplo, la geografía suele considerarse como una disciplina puente entre las ciencias y las letras. En nuestro país, se ha estimado, sobre todo, materia humanística.

Si se apuesta por un enfoque racionalista de la ciencia como actividad altamente lógica y ordenada que intenta comprender cómo es el mundo independientemente de nosotros, la geografía nunca podrá considerarse como tal. Solamente, algunos procesos contemplados por la geografía física pueden ajustarse a leyes matemáticas. Pero como ha demostrado Feyerabend (1992), ningún método científico racionalista es satisfactorio. Según este autor, la historia de la ciencia demuestra que todas las reglas científicas se han infringido en un momento u otro y que el saber científico no es más importante que los demás tipos de conocimientos.

En 1962, Orlando Ribeiro, al meditar sobre el carácter científico de la geografía, hacía la siguiente sabia reflexión ${ }^{1}$ : «Ciencias con objeto, método y leyes, tal como son indicadas en los manuales de Lógica, no existen fuera del dominio del mundo físico y orgánico. Las Ciencias Humanas, o las Ciencias de la Tierra que poseen también contenido humano, como la Geografía, son muchas veces variadas en el objeto y los métodos y rara vez conducen a leyes formuladas de manera concisa e invariablemente repetidas para explicar la relación de los fenómenos entre sí. ¿Dejan de ser, por ello, ciencias? De forma constante se procuran una objetividad, una precisión, estableciendo aproximaciones y correlaciones entre lo que es vario, mutable y se puede combinar de maneras diversas e imprevistas. En nombre, precisamente del espíritu científico no se debe simplificar lo que es complejo ni considerar «necesarias y previsibles» las relaciones contingentes y variables con que se producen los hechos. La Ciencia es una ACTITUD: Partiendo de la observación, ordena y aproxima los hechos procurando encontrar un nexo explicativo y construye con ellos un relato coherente, navegando con prudencia en un mar de variedades; ésta es la manera de trabajar del geógrafo. ¿Acaso es más imprecisa que la de un naturalista?» (sic).

Esta discusión sobre el carácter científico de la geografía, presente con excesiva reiteración en la historia del pensamiento geográfico, es, en mi opinión, un debate estéril, muestra de incomprensibles complejos de inferioridad que han atormentado, a lo largo de la historia de la disciplina, a algunos colegas con ideas poco claras de lo que debe ser su

1 Vid. Ribeiro, O. (1987): Introduçao ao estudo da geografia regional, ediçoes Joao Sa da Costa, Lisboa, pp. 10-11. 


\begin{tabular}{|c|c|c|c|c|c|}
\hline 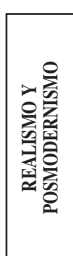 & 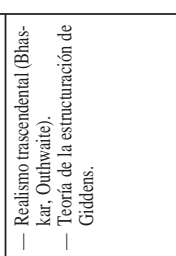 & 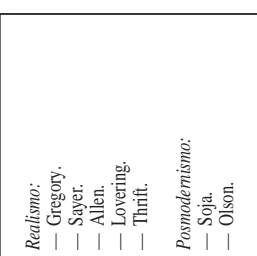 & 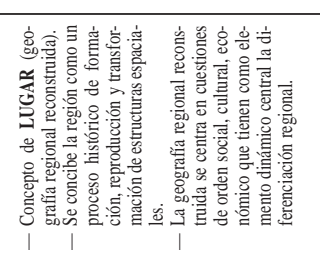 & 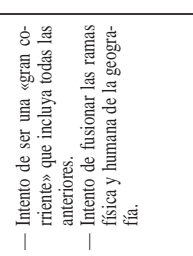 & 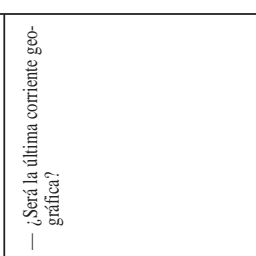 \\
\hline 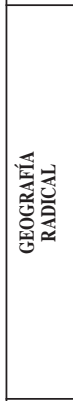 & 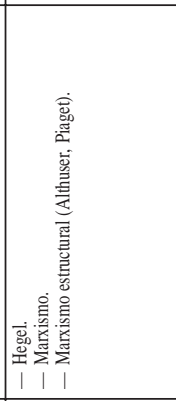 & 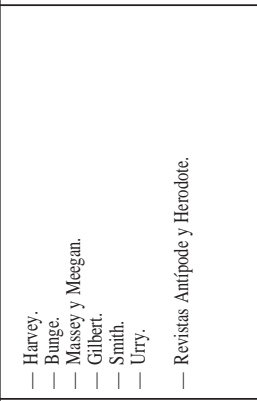 & 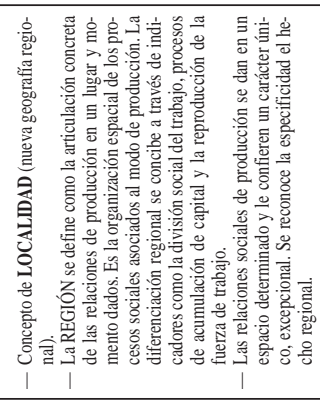 & 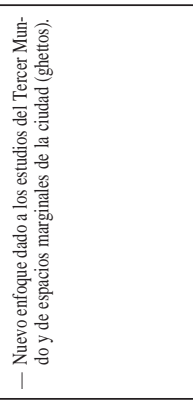 & 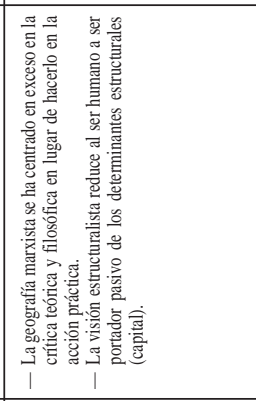 \\
\hline 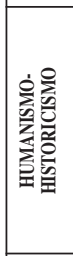 & 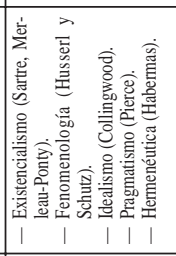 & 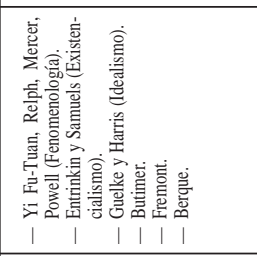 & 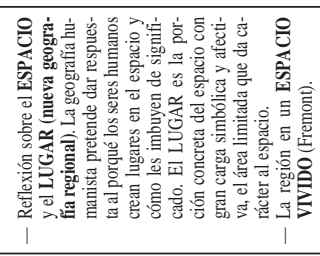 & 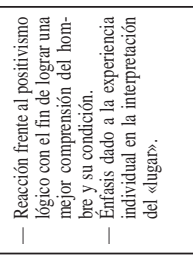 & 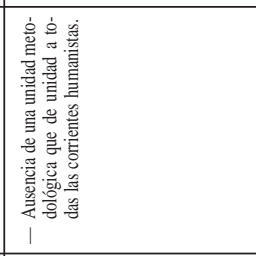 \\
\hline 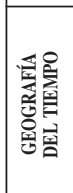 & & 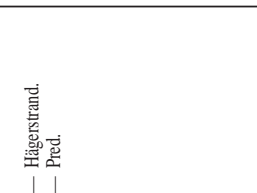 & 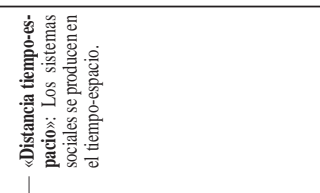 & 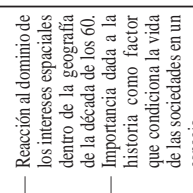 & 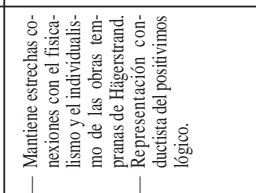 \\
\hline 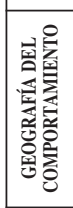 & 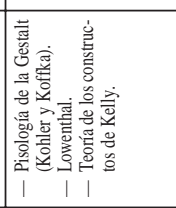 & 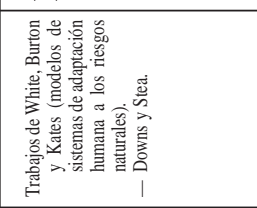 & 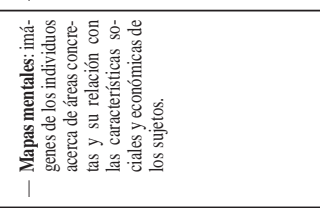 & 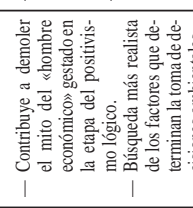 & 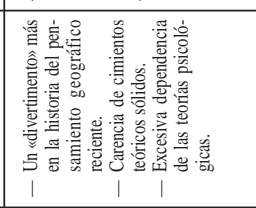 \\
\hline 雪 & 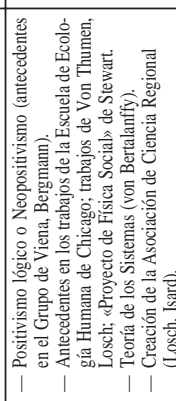 & 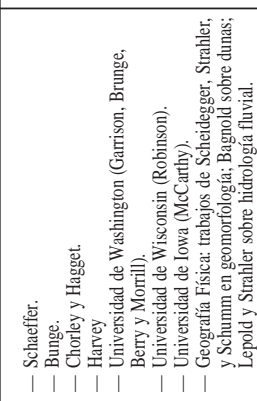 & 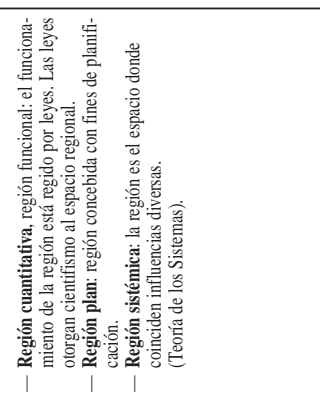 & 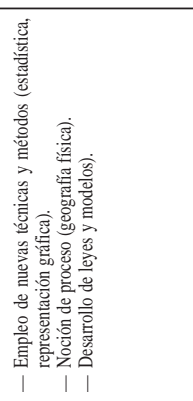 & 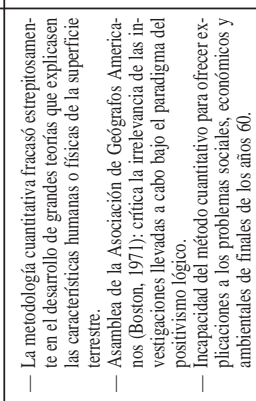 \\
\hline & 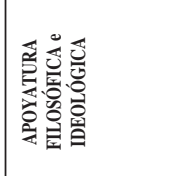 & 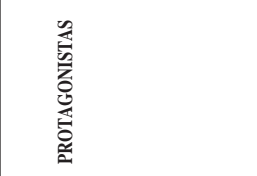 & 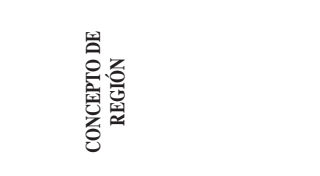 & 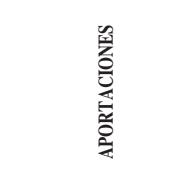 & 曾 \\
\hline
\end{tabular}


labor. La geografía es algo más que una ciencia: es un modo de entender la realidad existente, una manera de explicar cómo se relaciona el hombre con su medio natural y cómo se presentan estas relaciones en la superficie terrestre. Para ello sirven paradigmas, métodos y técnicas distintas, pero el objetivo final siempre es el mismo. Esto, a mi entender, otorga a la disciplina geográfica una categoría superior dentro de la estructura del conocimiento humano.

Junto a la reflexión sobre el carácter científico de la disciplina, otra de las cuestiones que ha marcado la explicación de la tradición geográfica es la aceptación de la división del pensamiento geográfico en dos grandes etapas: la pre-científica y la científica, y, en esta última, la organización en períodos que responden a la apuesta por una determinada apoyatura filosófica o, como llamó Kuhn, paradigma. No hay manual de historia de la geografía que no incluya esta división en etapas y corrientes. Por doquier se acepta el brusco corte que considera un antes y un después de Humbolt y Ritter en el desarrollo científico de la geografía. En mi opinión, resulta poco apropiada esta división en dos grandes etapas: precientífica y científica; esta última inaugurada por Humbolt y Ritter con el avance del s. XIX. Es cierto que en la larga etapa anterior - ¿precientífica?-, no hay una sistematización precisa, no hay paradigmas, hay carencia de aparataje y de mediciones exactas, pero hay preocupación por entender el mundo conocido y desconocido, hay inquietud por calibrar sus dimensiones, por medir distancias, en definitiva, hay explicación de hechos geográficos. La evolución del pensamiento científico (geográfico, en nuestro caso) es una lucha por mejorar los conocimientos de épocas precedentes, es, en suma, un avance constante de las inquietudes del hombre. En las distintas épocas históricas, el objetivo final ha sido idéntico: ensanchar el campo del conocimiento humano; lo que ha variado ha sido la posibilidad de disponer de medios técnicos cada vez más precisos, hecho que ha posibilitado, a su vez, la aparición de nuevos paradigmas. El grado de cientifismo en geografía no debe establecerse en función de mejoras técnicas o de paradigmas, sino de la valoración de la calidad de los trabajos dedicados a explicar lo esencial: las relaciones entre el medio y el hombre.

Sentado esto, la historia de la reflexión geográfica es un camino de aciertos y errores. La llegada de una nueva forma de hacer geografía, la aceptación de un nuevo paradigma gestado bajo la influencia de una apoyatura filosófica no tiene porque suponer una ruptura radical con lo anterior. Los extremismos son siempre negativos para la evolución de un conocimiento científico. Apostar con ofuscación por los principios de una corriente de pensamiento - geográfica, en nuestro caso - es demostrar escasa amplitud de miras y aún más si esta apuesta implica un rechazo indiscriminado hacia las doctrinas precedentes. Incomprensible y cicatera resulta la actitud, por parte del profesorado, de obligar al alumno a tomar partido por una u otra corriente geográfica, - sobre todo si esto ocurre en los cursos iniciales de carrera-, en un intento de conducir sus primeras inquietudes hacia las pretendidas verdades absolutas ideadas por tal o cual autor. Estas posturas, vigentes, por lo demás, en la universidad española, suelen manifestar escaso talante crítico en la formación del docente y desconocimiento de la reflexión geográfica en su totalidad; en suma, provocan deformaciones en la preparación académica de los futuros licenciados. El geógrafo preocupado por las cuestiones de epistemología debe adoptar una actitud crítica que le ayude a ponderar los aciertos y fracasos de cada etapa de la tradición geográfica y transmitirlo, así, a las futuras generaciones.

Sirva lo expresado para indicar que el progreso del pensamiento geográfico debe entenderse como un camino único de mejora del conocimiento, donde la división en etapas responde, únicamente, a utilidad o comodidad didáctica. Así, se puede afirmar que la evolución del pensamiento geográfico comprende unos antecedentes que integran el con- 
junto de aportaciones primeras a la disciplina geográfica desde la época griega hasta el siglo XVI, unas bases o etapa donde se consolidan los cimientos de pensamiento de la disciplina geográfica a través de la obra de Varenio, y sobre todo de Kant, Humbolt y Ritter; la etapa clásica, o período que transcurre desde la institucionalización académica de la disciplina geográfica hasta los años cuarenta de nuestro siglo, donde se contiene, en mi opinión, lo esencial del pensamiento de la geografía entendida como ciencia que estudia las relaciones entre el medio y el hombre y su diversa distribución en la superficie terrestre: en opinión de Storddart el período en el que existía «una geografía, la geografía». Y, por último, el aluvión de corrientes geográficas aparecidas desde mediados del siglo $\mathrm{XX}$, que comprende desde las concepciones funcionales de la geografía y del espacio regional hasta el interés actual por los estudios del «lugar» que se revelan en la llamada «nueva geografía regional» (vid. cuadro I).

\section{A.1. Sobre la actitud del geógrafo ante el pensamiento geográfico y las «filosofías geográ- ficas» recientes}

Cabe hacer una serie de apreciaciones personales sobre la evolución experimentada por el pensamiento geográfico, sobre la actitud del geógrafo ante esta reflexión y el papel que debe jugar la geografía en la sociedad actual.

Desde los años setenta, con la crítica al positivismo lógico que había azotado el edificio geográfico tras la segunda guerra mundial, la formulación en tropel de nuevas corrientes han perjudicado más que beneficiado a la disciplina geográfica. La asunción, sin más, de pensamientos de otras disciplinas (psicología, filosofía, economía política) ha desembocado en la pérdida de crédito social de la geografía que, de forma evidente, se plasma en nuestro país en el exiguo papel otorgado a la geografía en las enseñanzas no universitarias.

Se ha llegado a casos tan irracionales, tan poco geográfico, como las ideas defendidas por la corriente fenomenológica, que apuesta por los intentos introspectivos e intuitivos y por las categorías subjetivas para obtener conocimientos válidos. Como señala Hagget (1987), de manera irónica, para un fenomenólogo, «los Great Plains de EE.UU. son un desierto si la persona o grupo que en ellas se asienta cree que lo son y actúa en consecuencia. Si aceptamos esto, imagínense los nuevos horizontes que se abren para la geografía práctica, para aquella basada en la elaboración de propuestas de ordenación territorial: a partir de aquí todo está permitido para la reflexión geográfica.

Otro problema asociado a la aparición, en tropel, de corrientes humanistas en la geografía ha sido el progresivo distanciamiento entre las ramas física y humana de la disciplina. Unwin (1995) se hace eco de estos enfrentamientos en el mundo anglosajón, donde los partidarios de la geografía física no han aceptado las nuevas formulaciones y se han aferrado, por lo general, a los principios del positivismo lógico cuantitativo. A tal efecto, algún autor anglosajón no ha tenido reparo en señalar que «la geografía física ha llegado a ser una ciencia natural de verdad con gran dependencia en el desarrollo y aplicación de técnicas precisas de control, análisis y creación de modelos». En esta línea, los geógrafos físicos han fortalecido sus vínculos con los científicos de disciplinas como la geología, ingeniería y biología. Esta actitud, se puede apreciar, asimismo, en algunos colegas hispanos, que se autocalifican de «expertos» porque aplican modelos y emplean ordenadores en el estudio del cambio climático o de la supuesta desertización que invadiría nuestras tierras peninsulares.

Todo esto ha contribuido, además, a fomentar desánimo y falta de interés, entre los miembros de la comunidad geográfica, ante las cuestiones de pensamiento y método geográfico. De manera que, en función del grado de inquietud por las cuestiones de 
epistemología, una rápida caracterización de los miembros de la comunidad geográfica permitiría distinguir entre:

— los «pensadores», es decir, los verdaderos protagonistas de la evolución del pensamiento geográfico. En este escogido grupo se distinguen, además, realidades muy contrastadas: por un lado, los pensadores sensatos, los verdaderos «maestros», que han reflejado y reflejan en sus escritos el ejercicio de su labor y reflexión geográfica; frente a éstos, los pensadores extremistas o radicalizados, los «mesías» - generalmente procedentes del mundo anglófono-, es decir, los que, en un intento de sobresalir en el panorama del pensamiento de su ciencia, han trasladado al papel los frutos de unos arrebatos mentales escasamente fundados en una práctica de campo previa.

- los que no se interesan por las cuestiones de método porque, en el fondo, no les gusta su oficio; son los «librepensadores», es decir, los que se declaran liberados de pensar; conglomerado heterogéneo de situaciones que vegetan en el panorama universitario con el único afán de recibir la soldada mensual.

- y, por último, los que, reconociendo la importancia de las cuestiones de métodos y pensamiento en su quehacer geográfico, contemplan éstos con cierta lejanía, porque se dedican a «hacer geografía». Realidad de profesionales que han entendido la finalidad social de su quehacer y dan buena cuenta en su cotidiana práctica.

La práctica de una geografía seria, comprometida con los problemas que la sociedad reclama en cada momento, debería ser, sin duda, la aspiración de cualquier joven inquietud que se inicia en la carrera geográfica. El conocimiento de los soportes filosóficos en los que se ha apoya la geografía en su devenir, desde una posición crítica, es una apuesta irrenunciable del geógrafo; cuestión distinta es dejarse deslumbrar por las excelencias que proclaman algunos iluminados que, sin conocer bien, su función social, se han dedicado a hacer ejercicios mentales relacionando su reflexión teórica con las corrientes filosóficas del momento. En atinada frase de un maestro, «eruditos a la violeta», en cuyos pensamientos «hay mucho de hojarasca y muy poco de aprovechable».

Cierto es que, en nuestro país, la práctica geográfica ha estado, —igracias a Dios! —, ajena, en gran medida, a los nuevos hallazgos epistemológicos de la disciplina gestados allende las fronteras y sólo en los últimos años, con ocasión de la puesta en marcha de los nuevos planes de estudio, que han incorporado asignaturas de teoría y métodos de la geografía, ha surgido un interés por difundir el pensamiento geográfico, plasmado en numerosas ofertas editoriales.

En esto del quehacer geográfico creo que al escribir, al investigar, al hacer geografía, debe uno «sentir» la tarea que lleva a cabo y en esa actitud influye la propia habilidad del geógrafo que pone en práctica los conocimientos adquiridos de las personas que reconoce como maestros en los años de estudiante o investigador. Si uno no «siente» la geografía que escribe e investiga corre el peligro, por otra parte generalizado, de dejarse fascinar por las «maravillas» que ofrecen las corrientes filosóficas, las modernas técnicas de representación geográfica, en suma por las ideas «deslumbrantes» que proclaman ciertos «mesías» que abundan, por desgracia, en nuestra disciplina.

\section{A.2. Sobre la región y la nueva geografía regional}

Como indica Brunet (1990) la región es probablemente la palabra más oscura y controvertida de la geografía. Del recorrido por la historia del pensamiento geográfico y la evolución del concepto de región se extrae una conclusión evidente, siempre esgrimida por los geógrafos regionales: la falta de una definición universalmente válida y aplicable de REGIÓN. 
Esto no debe ser un hándicap para la labor regional de la geografía. Antes al contrario, la riqueza de contenidos existentes en relación al concepto regional, proporciona gran versatilidad al geógrafo regional interesado en la tarea de elaborar propuestas de regionalización del territorio.

Sobre el concepto de región y la labor de regionalización merecen realizarse las siguientes reflexiones:

- La región es un concepto de elaboración mental y personal. Es decir, cada geógrafo que participa en procesos de regionalización de una área específica, elabora un división territorial en función de los objetivos perseguidos en su tarea.

- Ello no obsta para reconocer la existencia de un distinto grado de subjetividad implícito en la catalogación de las unidades regionales. Así, las entidades de análisis espacial más objetivas son las REGIONES NATURALES; en efecto, las divisiones regionales fundadas en criterio natural, son reflejo de realidades existentes en la superficie terrestre. A partir de aquí el grado de subjetividad aumenta en las regionalizaciones de criterio político, económico y, sobre todo, social, puesto que la manera de entender la realidad de una territorio varía de un geógrafo a otro en función de la propia formación (física, humana, económica) y de la posible influencia de corrientes externas (paradigmas).

- Con un enfoque aplicado de la tarea regional, la región viene definida como UNIDAD TERRITORIAL ${ }^{2}$ en un sentido amplio, un marco espacial, de entidad variable, que el geógrafo debe interpretar, caracterizar y singularizar en su apasionante tarea de establecer propuestas de ordenación eficaces. Aceptado esto, resulta obvio que el geógrafo regional trabaja, según sus objetivos, sobre entidades territoriales de escala diversa (ámbito, dominio, zona, estado, región, provincia, ejes, comarca...), considerando los cambios de escala como signo de su habilidad de análisis que contribuyen a enriquecer, en último grado, la síntesis regional.

Sobre el actual proceso de renovación de la geografía regional (nueva geografía regional) debe señalarse que, por el momento, se sitúa en el estadio de reflexión teórica. De nuevo la geografía debe acudir a apoyaturas filosóficas externas para construir los cimientos de su ciencia y ello es lo más criticable de la renovación de los estudios regionales que se está fomentando desde el mundo anglosajón.

Dos opiniones opuestas merece este proceso: por un lado, la apuesta por los estudios del «lugar» como espacio social parece tener muy poco en cuenta la realidad de unos procesos económicos-políticos que son los que, en la actualidad, rigen los intentos de regionalización mundial. Por otro lado, me parece acertada resulta la consideración del territorio como «espacio vivido» en los estudios regionales, siempre y cuando ello no conduzca de nuevo a la práctica conductista que sacudió el edificio geográfico en los años setenta.

En España se percibe poco, en la práctica geográfica diaria, el actual debate existente en el mundo anglosajón sobre la renovación de la geografía regional. Aquí, - y creo que con cierto-, nos hemos dedicado a trabajar, hemos permanecido en nivel que Kuhn denomina de «ciencia normal», es decir, en un período no revolucionario de pensamiento. Y ello no nos coloca en una posición inferior respecto a los colegas de allende las fronteras; antes al contrario, estos últimos aprecian la labor geográfica desarrollada en

2 Emilio Murcia, en su lúcida reflexión sobre el papel de la geografía en el sistema de las ciencias, indica que el objeto de estudio de la geografía, en el marco de la Teoría General de Sistemas, es el sistema territorial que se define como el conjunto de «unidades territoriales significativas», es decir, partes de la superficie terrestre, sin connotación dimensional alguna, que tiene una significación especial para el hombre que vive y actúa sobre ella. (Vid. Murcia Navarro, E. (1995): La Geografía en el Sistema de las Ciencias, Universidad de Oviedo, Servicio de Publicaciones, pp. 187-200). 
España. Una visita a Europa, mediante la participación en reuniones de programas Erasmus (Socrates) revela esta creencia. En España se «hace» buena geografía regional, ajena a las calenturas epistemológicas de países anglosajones.

Por último, sobre el futuro de la labor regional en geografía, creo que un campo de trabajo, de amplia tradición en la disciplina que merece una consideración mayor es el PAISAJE. Entendiendo por tal una unidad territorial con entidad propia y diferenciada de otras en función de aspectos culturales (sociales, económicos, político) y que se asienta sobre un medio físico al que transforma en virtud de la cultura vigente, el paisaje es una unidad de trabajo geográfico con mayor capacidad didáctica que la región por los «aspectos visuales» que se contienen en su identificación. El fomento de los estudios del paisaje, en un sentido amplio, a la manera de Sauer o Troll, es una labor todavía en ciernes en la investigación y docencia geográfica española.

\section{B. Lo que la geografía debe ser: reflexiones personales}

La presente reflexión caería en el mismo error que se ha denunciado en el proemio de este trabajo si no se incluyesen una serie de propuestas ilusionantes sobre el papel que, en mi opinión, debe jugar la geografía y el geógrafo en el tiempo inmediato, sabedores que tenemos ahora la díficil misión de preparar los contenidos geográficos que se impartirán a los futuros geógrafos, que ha tenido ya un primer eslabón en la puesta en marcha de las nuevas licenciaturas en geografía. En este momento, todavía de desconcierto, es necesario ofrecer propuestas que ayuden a rescatar el áura perdida por la geografía y nos coloquen, sin complejos, en posición de igualdad junto al resto de disciplinas, antiguas o nuevas, que han ido carcomiendo, con nuestro consentimiento, la estructura de los contenidos propios de nuestra ciencia.

\section{B.1. Sobre la vertiente aplicada de la geografía}

La apuesta por la utilidad de los conocimientos que se investigan en la tarea geográfica cotidiana debe ser objetivo básico para el geógrafo comprometido con su ciencia. En su reflexión sobre el futuro de la geografía, Hagget (1987) señalaba que «es probable que la geografía se oriente con mayor fuerza hacia campos aplicados y problemas prácticos».

La idea de la utilidad práctica de la geografía no es nueva, a pesar que en nuestro país, la consideración académica oficial de la geografía aplicada se ha producido recientemente en el marco del proceso de renovación de la Licenciatura Geográfica. Ya Hettner en su obra La Naturaleza y los cometidos de la Geografía (1927), dedica un apartado a «la geografía práctica» señalando que la geografía, desde la Antigüedad, ha estado durante mucho tiempo al servicio de la vida práctica e indicaba como los manuales de geografía y los atlas han dedicado su atención a las necesidades de orientación exterior y a intereses prácticos. Hettner señalaba, con gran acierto, que «no deja de ser un error cuando algunos científicos intentan desvincular totalmente a la ciencia de la vida». Entre las tareas de la geografía práctica, Hettner proponía dos cuya finalidad, por encima de cambios de denominación asumidos en la disciplina geográfica, bajo la influencia de la ciencia regional y la planificación económica, se mantiene en la actualidad:

- la valoración, «que no se conforma con el conocimiento de los hechos y sus causas sino que investiga qué valor tienen las condiciones geográficas para el hombre, cómo sirven a su necesidades materiales e ideales, qué posibilidades de sustento y de lucro le ofrecen, en qué sentido influye en su vida y su carácter».

— las propuestas sobre modificaciones como fundamento inmediato de la iniciativa. 
Empero, el deseo de aplicación de la teoría a la realidad, es decir, la consolidación de la geografía práctica encuentra en los años de posguerra del segundo conflicto bélico mundial un contexto idóneo de desarrollo. La gestación entonces de la ciencia regional animó a algunos geógrafos a entrar en contacto con las ideas de los economistas con el fin de no sólo contemplar o examinar la región sino de «actuar sobre ella». Surge entonces los conceptos de región aplicada y ordenación territorial. En Francia Philipponneau advierte, en 1960, de los beneficios de la dimensión aplicada que deben poseer las investigaciones geográficas. Para este autor la ordenación del espacio constituye el campo más amplio de las aplicaciones de la Geografía, pues en él donde el geógrafo manifiesta sus dos cualidades esenciales: sentido de síntesis y de espacio. Bajo esta concepción aplicada de la función de la geografía, se desarrollarán los trabajos de Juillard, Tricart, o Labasse. Tricart, en 1958, señala que la geografía aplicada no es una nueva disciplina, «es solamente un enriquecimiento de la geografía» e indica que «una ciencia puramente académica es una ciencia mutilada que, manteniéndose deliberadamente apartada del estímulo y del control de la práctica, se arriesga a extraviarse en callejones sin salida, a despilfarrar esfuerzos meritorios con toda esterilidad. Pero, asimismo, alertaba sobre «el riesgo de hacer de la geografía aplicada una simple receta, una técnica limitada de prácticas sin horizontes. Por su parte, Jean Labasse, en su excelente manual sobre geografía aplicada La organización del espacio, señala que «en definitiva, la aportación más interesante del geógrafo para la remodelación de los territorios, no reside ni en sus métodos de trabajo ni en sus maneras de razonar, sino en lo que hay de verdaderamente innato en su actitud: este sentido de la contingencia que lleva a insertar cada cosa en su contexto y a romper constantemente la unidad artificial de las presentaciones amplias y seductoras».

En la URSS, la doctrina marxista tampoco se olvidó del plano pragmático de la geografía llevada a cabo en organismos oficiales como el Instituto de Geografía de la Academia de Ciencias de la URSS. Se adopta aquí la expresión «geografía constructiva». Al respecto Guerassimov señalará, en 1976, que «en la etapa actual la geografía se ha convertido en una ciencia compleja constructiva y transformadora».

En España, el lento despertar de la Geografía aplicada arranca, según Campesino Fernández (1989), con los planteamientos territoriales surgidos a partir del cambio político que propicia la construcción del nuevo Estado de las Autonomías. No se deben olvidar, empero, antecedentes sobresalientes de la práctica aplicada de la disciplina geográfica en nuestro país como la División Territorial de Cataluña (1932) realizada por Pau Vila, la creación del Departamento de Geografía Aplicada de Zaragoza, bajo la dirección del profesor Casas Torres o la gestación del Instituto de Geografía Aplicada en 1967, adscrito al C.S.I.C. No obstante, hasta la década de los ochenta no se toma conciencia de las posibilidades de aplicación del trabajo geográfico en la resolución de problemas que plantea la sociedad.

En efecto, los últimos lustros han conocido una creciente participación de los geógrafos en estudios y proyectos de carácter aplicado. La colaboración en estudios de impacto ambiental, en planes de desarrollo local, comarcal o regional, en memorias sobre cuestiones medioambientales, en revisiones de planes de ordenación urbana, en propuestas relativas a transportes es una aspiración que debe tener presente el geógrafo académico como desarrollo de la investigación fundamental y perfeccionamiento incesante de las técnicas de trabajo. El desarrollo de las modernas técnicas de representación (tratamiento digital de imágenes y sistemas de información geográfica) ha sido decisivo en el proceso de creciente «aplicación» de los contenidos geográficos.

La intervención de los geógrafos en trabajos de orientación aplicada merece algunas consideraciones: 
- En primer lugar, la participación del geógrafo docente universitario en proyectos financiados por agentes sociales públicos o privados debe tenerse como un medio de transmitir los conocimientos desarrollados en la investigación universitaria mediante su aplicación a problemas concretos planteados. En ningún momento, la colaboración en trabajos de orientación aplicada debe verse como un medio de incrementar los honorarios mensuales. La geografía práctica y aplicada no debe ser refugio de docentes geógrafos universitarios que se preocupan sólo por la adoración al becerro de oro, sin considerar los beneficios que su colaboración en los trabajos encargados debe suponer para su enriquecimiento científico y para la posterior docencia en las aulas.

- Respecto a los jóvenes licenciados que apuestan, como futuro profesional, por desarrollar equipos de trabajo para su intervención en trabajos de corte aplicado, se debe señalar que esta función social implica la necesidad de una formación sólida y brillante durante los años de licenciatura, y la obligación, posterior, de constante perfeccionamiento de los conocimientos para llevar a cabo dignamente su labor. Se ha extendido, erróneamente, la idea de la superioridad del colectivo geográfico sobre otros profesionales en la práctica profesional. Ello parece otorgar excesiva confianza a los jóvenes licenciados que consideran que lo aprendido en las aulas es suficiente para desarrollar las tareas encargadas. Cierto es que el geógrafo parte con unas ventajas a la hora de enfrentarse con un problema de ordenación territorial: su capacidad de síntesis, su visión «humanista de los hechos», es decir, la consideración del pasado como elemento a considerar en la posterior planificación, su destreza a la hora de fundir, racionalmente, conocimientos de diversas disciplinas. Esta labor exige, por tanto, una formación previa muy sólida. Richardson, afirma, al respecto que «los geógrafos que prevean trabajar en el sector privado deben alcanzar la mejor y más amplia formación posible». No es suficiente argumentar la posesión de un «curso» de teledetección o de cartografía automatizada como aval para encontrar abiertas las puertas de un futuro profesional «aplicado». A largo plazo, la técnica, aunque importante, no sustituye al conocimiento sustantivo y a la aguda capacidad analítica. Ello afirma la necesidad de una educación amplia que otorgue al joven geógrafo la capacidad para plantear correctamente y entender las complejas interdependencias que se dan en el espacio. El profesor García Fernández (1978) era ya concluyente al respecto al afirmar, con gran acierto, en referencia a la participación del geógrafo en los procesos de planificación urbana, que «para que se inserte en la planificación no basta con que el geógrafo haga votos de su utilidad, sino que adquiera crédito para ello. Y sólo obtendrá la beligerancia necesaria, primero, con estudios de geografía urbana de gran calidad, claros y sobre todo legibles; y después demostrando con espíritu crítico, aportar soluciones serias y libres de todo arbitrismo, para una mejor construcción de la ciudad».

El fomento de la educación geográfica aplicada, por la que ha apostado decididamente el proceso de renovación de las enseñanzas geográficas en nuestro país, deberá servir para difundir la experiencia aplicada de los geógrafos docentes universitarios en ejercicio, en aras a la formación de las nuevas generaciones. Las nuevas asignaturas «aplicadas» que se contemplan en la troncalidad del nuevo plan de estudio de la licenciatura en Geografía deben incluir contenidos «aplicados» efectivos y no con consideraciones supuestamente aplicadas de los conceptos teóricos de siempre. Ello sólo podrá darse en los departamentos que disfruten de tradición en la participación en proyectos y trabajos de orientación aplicada. ¡¡Ojalá sea así por el bien de la formación de los futuros licenciados!!

\section{B.2. Sobre la labor del docente geógrafo}

La vigente Ley de Reforma Universitaria (Ley Orgánica 11/1983, de 25 de agosto) es 
clara al señalar las funciones básicas que debe cumplir la Universidad española, en el umbral del siglo XXI, y, por ende, el personal docente a ella adscrito. El desarrollo científico, la formación profesional y la extensión de la cultura se destacan como los tres pilares en los que debe descansar la tarea universitaria. Por tanto, el docente e investigador universitario debe aspirar a:

- realizar buenas investigaciones, comprometidas con las demandas que reclama la sociedad de su tiempo.

- dedicar el tiempo necesario a «formarse para formar», es decir, ser un docente constantemente preocupado por los contenidos a impartir en las aulas.

- difundir sus conocimientos al resto de la comunidad no universitaria que espera de él soluciones y explicaciones a problemas específicos.

La primera de estas funciones nos habla del papel investigador del funcionario docente universitario. Se ha señalado la necesidad de realizar investigaciones buenas y comprometidas, es decir, de calidad, que supongan siempre un avance o complemento de los conocimientos ya existentes y que tengan un sentido social, esto es, que intenten responder a problemas de la sociedad que demandan una respuesta eficaz. La legislación universitaria vigente obliga al funcionario docente universitario a realizar investigación, tarea, en mi opinión, esencial puesto que no se puede concebir buena docencia sin buena investigación previa e igualmente no hay buena transmisión a la sociedad de los logros conseguidos en la tarea investigadora sino se tiene presente el ideario docente del profesor. El art. 1.1 de la Ley Orgánica 11/1983, de 25 de agosto, de reforma Universitaria, señala que «son funciones de la Universidad al servicio de la sociedad: la creación, desarrollo, transmisión y crítica de la ciencia, de la técnica y de la cultura». La inquietud de la Administración en materia de investigación científica queda claramente expresada con la promulgación de la Ley 13/1986, de 14 de abril, de fomento y coordinación general de la Investigación Científica y Técnica, en la que se contiene una detallada regulación de la actividad científica en nuestro país. En ella se recoge la creación del Programa Nacional de Investigación Científica y Desarrollo Tecnológico, sus objetivos y programas y normas de funcionamiento.

Esta preocupación por el desarrollo de la investigación es complementada por los propios Planes de Investigación y Ciencia desarrollados en aquellas Comunidades Autónomas con competencias de educación transferidas. El funcionario docente universitario tiene, como misión básica, estar al corriente de las convocatorias de los programas anuales de investigación, con objeto de abrir vías de investigación en el seno departamental, mejorar la infraestructura de investigación existente e incorporar las inquietudes de jóvenes licenciados a las tareas de investigación desarrolladas en los Departamentos.

Sobre las obligaciones docentes poco debería insistirse. Debemos ser conscientes de nuestro papel ante la sociedad. Somos servidores públicos y, en nuestro caso concreto, debemos ser formadores de inquietudes. Junto a esta convicción personal, la normativa legal es clara. La Declaración universal de los Derechos Humanos, de 10 de diciembre de 1948 en su art. 26.1 señala que «toda persona tiene derecho a la educación» y, en relación con los estudios universitarios indica que «el acceso a los estudios superiores será igual para todos, en función de los méritos respectivos». Asimismo, el art. 27 de la Constitución Española, de 27 de diciembre de 1978 reconoce en su art. 27 que «todos tienen el derecho a la educación» y aún más «la educación tendrá por objeto el pleno desarrollo de la personalidad humana en el respeto a los principios democráticos de convivencia y a los derechos y libertades fundamentales». Queda claro, pues, el COMPROMISO SOCIAL al que estamos obligados los docentes en cualquier estrato de la educación, incluida la 
enseñanza universitaria. Ello exige una dedicación y atención permanente del profesorado hacia el alumno y una puesta al día en los contenidos a impartir en las aulas.

El art. 9 del Real Decreto 898/1985, de 30 de abril, sobre Régimen del Profesorado Universitario, detalla en su apartado $4^{\circ}$ el régimen de dedicación al que está comprometido el profesorado. La falta de cumplimiento de esta norma, junto a otras de régimen interno de los Departamentos que se detallan en el articulado del Real Decreto 898/1985, pueden desembocar en la aplicación de sanciones cuya reglamentación ocupa los artículos 17 y 18 de dicha normativa, pudiendo llegar incluso a la «deducción proporcional de todas las retribuciones» (art. 18.1). Además, la normativa de rango superior relativa a la Función Pública, a la que está sometido asimismo el Cuerpo de Docentes Universitarios, (Ley 30/1984, de 2 de agosto, de medidas para la Reforma de la Función Pública) señala en su art. 31.1, apartado f (sobre el régimen disciplinario) que se consideran faltas muy graves «la notoria falta de rendimiento que comporte inhibición en el cumplimiento de las tareas encomendadas».

Sirva este recordatorio a la normativa legal vigente en materia educativa, para remarcar el carácter de COMPROMISO SOCIAL que adquiere cualquier aspirante o integrante de los cuerpos de funcionarios del Estado (o en su caso, de la Comunidad Autónoma).

No es casualidad, porque así se contempla en el art. 16 del referido Real Decreto 898/1985, que se asista, en la actualidad, a la creación de órganos o comisiones de control de seguimiento de la disciplina académica en aras a la mejora constante de la calidad de la enseñanza. En cualquier caso, el acceso a un puesto de la Administración (en este caso, educativa) no debe suponer la adquisición de un «status» que ocasione, ante la seguridad de los emolumentos mensuales, relajación de las obligaciones que el funcionario contrae ante la sociedad.

En suma, el docente geógrafo universitario debe regirse, como norma de actuación comprometida, por el cumplimiento estricto de horarios de trabajo, la atención permanente al alumno, la preparación y mejora constante de los contenidos docentes, en suma, la «ilusión por enseñar» $\mathrm{y}$, asimismo, la colaboración con los distintos agentes sociales que reclaman en sus conocimientos la búsqueda de soluciones ante problemas concretos. Con el proceso reciente de renovación de las licenciaturas, se ha abierto un nuevo período en la docencia universitaria que exige la colaboración de todo el colectivo geográfico universitario para otorgar a nuestra disciplina el rango que merece en la sociedad española. Y ello sólo podrá ser si nos exigimos a nosotros mismos en nuestra labor cotidiana y si participamos con convicción en las decisiones que afecten al futuro de nuestra ciencia.

Por último, el docente e investigador universitario debe mantener el compromiso de informar a la sociedad de aquellos avances obtenidos en sus investigaciones que sirvan para el beneficio común. Así se reconoce en el art. 1.2 de de la Ley Orgánica 11/1983, de 25 de agosto, de Reforma Universitaria, donde se indica que es función de la Universidad «la extensión de la cultura universitaria» (apartado d). En concreto el docente universitario geógrafo debe mostrar a la sociedad las mejoras metodológicas y conceptuales ocurridas en su disciplina a través de la participación en cursos de actualización de conocimientos llevados a cabo por Institutos de Ciencias de la Educación, Centros de Profesores de Educación Primaria y Enseñanza Secundaria. E igualmente, debe transmitir aquellos progresos que, en las diversas ramas geográficas, contribuyan al progreso de la sociedad para la que orienta sus investigaciones.

\section{B.3. Propuesta de modificación de las asignaturas troncales del plan de estudios de Geografía}

La aprobación de la Ley Orgánica 11/1983, de 25 de agosto, de Reforma Universitaria, inauguró un nuevo proceso de renovación de las enseñanzas superiores en España que afectó, asimismo, a la disciplina geográfica. 
Un primer efecto de la puesta en marcha de la L.R.U. fue la aparición y consolidación de las «Áreas de Conocimiento», al que ha seguido la actualización de los contenidos de las Licenciaturas, Arquitecturas, Ingenierías y Diplomaturas vigentes hasta ahora en la Universidad española. Así, en cumplimiento de los artículos 28 y 29 de la L.R.U., se promulgaría el Real Decreto 1.497/1987, de 27 de noviembre, por el que se establecen directrices generales comunes de los planes de estudio de los títulos universitarios de carácter oficial y validez en todo el territorio nacional. Las asignaturas que compondrán los nuevos planes de estudio se dividen, en virtud del mencionado Real Decreto en:

- Materias troncales, es decir, contenidos homogéneos mínimos de los planes de estudio que serán establecidos por las directrices generales propias.

- Materias no troncales, o contenidos formativos determinados discrecionalmente por la Universidad en los planes de estudios, bien como materias obligatorias, o bien como optativas para el alumno, y

- Créditos de libre elección por el alumno, que podrán ser aplicados por éste en orden a la libre configuración de su propio currículum.

Cada Universidad pública tiene potestad para elaborar y aprobar los planes de estudios conducentes a la obtención de los títulos universitarios oficiales con sujección a las directrices generales comunes que establece el R.D. 1.497/1987 que serán de aplicación tras homologación por el Consejo de Universidades. A partir de este momento, todos los Departamentos de las Universidades españolas entraron en un proceso desenfrenado de elaboración de los distintos planes de estudio.

La Geografía no fue ajena a este proceso; en 1990, se aprobó el Real Decreto 1.447/1990, de 26 de octubre, por el que se establecía el título universitario oficial de Licenciado en Geografía y las directrices generales propias de los planes de estudios conducentes a la obtención de aquél. Los aspectos más importantes contenidos en dicho Real Decreto fueron los siguientes:

- Apuesta por el carácter aplicado de la disciplina.

- División de las enseñanzas en dos ciclos: primero (dos o tres años), segundo (dos años).

- Carga lectiva global nunca inferior a 300 créditos.

- Aprobación de las asignaturas troncales.

La aprobación de las asignaturas troncales fue precedida de un período previo e intenso de debate donde se contrastaron las propuestas elaboradas por el «grupo de expertos» creado por el Ministerio de Educación y Ciencia con participación del colectivo geográfico (Grupo XIV) y las sugerencias elaboradas por las universidades, que quedaron recogidas en la publicación sobre la Licenciatura en Geografía del Consejo de Universidades ${ }^{3}$. Aspectos decisivos de estos debates fueron la creación, por primera vez en España, de un título de «Geografía» y el establecimiento de las asignaturas troncales de la Licenciatura que quedaron recogidas en el texto del Real Decreto 1.447/1990, de 26 de octubre.

De la implantación de la nueva licenciatura en Geografía en las diferentes universidades españolas se desprenden los siguientes aspectos:

- Se ha apostado, unánimemente, por una reducción del número de años académicos para la obtención del título de Licenciado (4 años). Se trata de una decisión no del todo meditada y que en el futuro se verá, sin duda, modificada conforme se observen las deficiencias — ya patentes — de los planes de estudio vigentes.

3 Vid. Consejo de Universidades (1988): Reforma de las Enseñanzas Universitarias. Título: Licenciado en Geografía, Secretaría General, Madrid, 163 p. 
— La implantación de «asignaturas nuevas» con «contenidos viejos», es decir, se han establecido nuevas materias con denominaciones atrayentes cuyos contenidos, empero, siguen siendo «los de siempre» sin adaptarse a las nuevas necesidades. Gold et alt. (1991) en un reciente estudio sobre la enseñanza de la Geografía en la educación universitaria comentan, con pleno acierto que «sospechamos que para muchos profesores de Geografía en los centros superiores, el problema educativo más importante es el de especificar el contenido geográfico de los cursos» ${ }^{4}$.

- Excesivo número de asignaturas cuatrimestrales que causan desconcierto en el alumnado al asistir a un constante trasiego de profesores a lo largo del año académico, y malestar entre el profesorado al sentirse incapaz de ofrecer en cuatro meses contenidos que merecerían impartirse en un año académico completo.

- Denominaciones pintorescas de algunas asignaturas que, en numerosas ocasiones, responden a querencias muy personales o a temas concretos tratados en trabajos doctorales.

Reconocer estos fallos debe motivarnos a mejorar el modelo y contenidos de las nuevas licenciaturas. El proceso de renovación de las nuevas licenciaturas comienza por las propuestas de modificación de asignaturas obligatorias de universidad y optativas de cada universidad, como contempla el art. 11 del Real Decreto 1.497/1987, de 27 de noviembre. No obstante, es obvio que el éxito o fracaso de un plan de estudios radica, junto al interés propio de los docentes en dar contenidos interesantes a las materias propuestas, en el acierto de las propuestas de troncalidad que deben contener, como su propio nombre indica, el armazón de la nueva licenciatura.

A tal efecto, estimo que el actual conjunto de materias troncales presentes en el Real Decreto 1.447/1990, de 26 de octubre no es representativo, a mi entender, de los contenidos esenciales y generales que se deben incluir en una licenciatura de geografía. En ánimo de contentar las exigencias de las distintas áreas de conocimiento geográficas se propusieron, en su día, una serie de materias troncales, algunas innecesarias, que olvidan algunos contenidos básicos para la formación del geógrafo, que no están bien distribuidas entre los dos ciclos de la Licenciatura y que, en definitiva, terminan por convertir ésta en un proceso tedioso.

Por ello se propone, a continuación, un nuevo modelo a tener en cuenta en un futuro proceso de renovación de dichas materias. Hay que señalar, de entrada, que el proceso de modificación de los planes de estudios contemplada en el art. 11 del Real Decreto 1.497/1987, de 27 de noviembre no resulta explícito a la hora de distinguir entre reforma de asignaturas troncales o de asignaturas determinadas discrecionalmente por la universidad. Tampoco indica nada, al respecto, el Real Decreto 1.447/1990, de 26 de octubre en el que se establecen las directrices generales de la licenciatura de Geografía. Se debe entender que la modificación de asignaturas troncales deberá realizarse por acuerdo entre Ministerio de Educación y colectivo de docentes geógrafos a propuesta de éstos.

En mi opinión, la filosofía última que rige la distribución de cursos a lo largo de la licenciatura es correcta; es decir, un primer ciclo de carácter «generalista» y una segundo ciclo de orientación «aplicada». Ha sido ésta una orientación perseguida por el colectivo geográfico de nuestro país a lo largo de los años ochenta. Conseguir aproximar los conocimientos impartidos en las aulas a la realidad socio-profesional del país es una apuesta básica

4 Vid. Gold, J.R. et alt. (1991): Teaching geography in higher education: a manual of good practice. Oxford Basil Blackwell. 
en aras a propiciar el mantenimiento de la geografía como disciplina básica en la formación cultural de la sociedad. En expresión de R. Brunet (1993), en el excelente opúsculo de geografía regional «Mundos nuevos» (p. 232), es apostar por una «geographie maintenant», es decir por una geografía que mantiene su bagaje y a la vez por una geografía del presente.

Aceptado este supuesto, estimo que las modificaciones futuras que merezcan las nuevas licenciaturas implantadas deberían volver al modelo de Licenciatura de 5 años que descarge la actual congestión de asignaturas y créditos por año. Y junto a ello, cabría hacer las siguientes consideraciones sobre los contenidos a impartir en cada curso de la Licenciatura y las asignaturas troncales más adecuadas en cada uno de ellos (vid. cuadro II):

\section{$1^{0}$ ciclo}

$1^{\circ}$ curso: El primer curso debe ser de formación geográfica «general». Una presentación general de las cuestiones básicas de la disciplina geográfica orientada a alumnos recién incorporados a la vida universitaria. Se trata además de alumnos que llegan a la universidad con una visión poco clara de lo que es la geografía puesto que en los cursos de bachillerato apenas han podido recibir contenidos geográficos. En este curso se deben impartir asignaturas troncales contempladas en el R.D. 1.447/1990 de «Geografía Física» y «Geografía Humana» y añadir una nueva de «Introducción al Análisis Geográfico Regional»

$2^{o}$ curso: En este curso el alumno junto a la consolidación de los conocimientos geográficos generales, debe comenzar a familiarizarse con el problema de las escalas de trabajo. Por ello se proponen como troncales las asignaturas ya contempladas de «Técnicas en Geografía» para las distintas áreas de conocimiento y se apuesta por la inclusión de una «Geografía Zonal», materia que esta siendo objeto de recuperación en Francia y que se presenta como enlace idóneo entre la formación «general» del primer curso y la formación «regional» que se entiende necesaria en el $3^{\circ}$ curso de la Licenciatura.

$3^{\circ}$ curso: Es un curso de formación «regional». En él junto a las asignaturas troncales establecidas de «Geografía de Europa» y «Geografía de España» es necesaria la inclusión de una «Geografía regional del mundo» que incluya una presentación global de la realidad de las diferentes regiones del mundo contemporáneo»; visión general que luego debe ser completada con la incorporación de asignaturas descriptivas de carácter obligatorio.

\section{$2^{\circ}$ ciclo}

$4^{\text {o }}$ curso: Es un curso de introducción a la formación práctica de la geografía. Las asignaturas más convenientes para este nivel serían las de «Geografía Física Aplicada» y «Geografía Humana Aplicada» contempladas ya en el R.D. 1.447/1990, a las que habría que añadir una «Geografía Regional Aplicada».

$5^{\circ}$ curso: o curso de orientación para el inmediato futuro profesional del geógrafo. Por ello junto a la especialización en geografía aplicada plasmado en las asignaturas troncales contempladas por el Real Decreto 1.447/1990 de «Ordenación del Territorio y Planificación» se debe incluir una «Didáctica de la Geografía» con vistas a los alumnos que apuesten por la docencia como ocupación profesional futura.

Se suprimen así, de este conjunto de materias troncales, las asignaturas de «Teoría y métodos de la Geografía» contempladas por el R.D. 1.447/1990, para el $2^{\circ}$ ciclo de la Licenciatura puesto 
Cuadro II

PROPUESTA DE MODIFICACIÓN DE LAS ASIGNATURAS TRONCALES DE LA LICENCIATURA DE GEOGRAFÍA

\begin{tabular}{|c|c|c|}
\hline CICLO & CURSO & ASIGNATURA TRONCAL \\
\hline \multirow{3}{*}{ PRIMERO } & $1^{\mathrm{o}}$ & $\begin{array}{l}\text { - Geografía Física } \\
\text { - Geografía Humana } \\
\text { — Introducción al Análisis Geográfico Regional }\end{array}$ \\
\hline & $2^{\circ}$ & $\begin{array}{l}\text { - Técnicas en Geografía } \\
\text { — Geografía Zonal }\end{array}$ \\
\hline & $3^{\circ}$ & $\begin{array}{l}\text { - Geografía de Europa } \\
\text { - Geografía de España } \\
\text { - Geografía Regional del Mundo }\end{array}$ \\
\hline \multirow[t]{2}{*}{ SEGUNDO } & $4^{\circ}$ & $\begin{array}{l}\text { - Geografía Física Aplicada } \\
\text { - Geografía Humana Aplicada } \\
\text { - Geografía Regional Aplicada }\end{array}$ \\
\hline & $5^{\circ}$ & $\begin{array}{l}\text { — Ordenación del Territorio y Planificación } \\
\text { — Didáctica de la Geografía }\end{array}$ \\
\hline
\end{tabular}

que los contenidos previstos en el propio Real Decreto no se ajustan a la filosofía de este segundo ciclo y bien pueden incorporarse a la Licenciatura, en todo caso, como materias obligatorias de universidad. Resulta incongruente la inclusión de estas asignaturas de «Teoría y métodos» en el segundo ciclo y las «Técnicas en geografía» en el primer curso de la licenciatura cuando la orientación que se presume para cada ciclo (generalista el primero y «aplicado el segundo») es ciertamente contraria con los contenidos a impartir en estas asignaturas.

\section{B.4.- Propuesta de cambio de denominación del área de conocimiento de "Análisis Geo- gráfico Regional»}

Se ha señalado, con anterioridad, la ausencia de una definición comúnmente aceptada del término REGIÓN, la riqueza de enunciados de dicha expresión que ha conocido y conoce la tradición geográfica, prueba evidente, por lo demás, de que se trata de un objeto de estudio siempre vivo y en constante evolución.

Asimismo, se ha indicado la riqueza de ámbitos de estudio con que trabaja el geógrafo y la importancia de los cambios de escala en los estudios regionales. Así, junto a la región, objeto clásico de trabajo de la geografía regional, el ámbito, el dominio, la comunidad autónoma o la provincia son, igualmente, objetos de estudio regional.

Por tanto, dos ideas destacan entre los principios de la geografía regional: la inexistencia de una definición universalmente aceptada del término REGIÓN y la importancia de los cambios de escala (cambio de espacio regional). Estos dos axiomas generalmente aceptados en la investigación geográfica, no han encontrado, sin embargo, equivalencia en la denominación del área de conocimiento «regional»vigente en la estructura académica universitaria de nuestro país: «Análisis Geográfico Regional».

En la estructura académica universitaria española la denominación del área de conocimiento «Análisis Geográfico Regional», surgió a comienzos de los años ochenta con la 
consolidación de las áreas de conocimiento, contemplada en la Ley Orgánica 11/1983, de 25 de agosto de Reforma Universitaria, guardando evidentes semejanzas con la expresión «Análisis Regional» de la corriente regional de los economistas, donde numerosos geógrafos han intentado redimir sus «complejos de inferioridad». Con esta expresión, los geógrafos renunciamos a dos aspectos: la síntesis regional, y la posibilidad teórica (de facto no se produce) de poder manejar otros espacios de mayor o menor escala como objeto de trabajo regional.

En primera aproximación, la denominación más ajustada para nombrar este área de conocimiento debería ser «Geografía Regional», entendida la región como el espacio actuado por el hombre en sus distintas facetas (económica, política, social, ambiental) y a diversas escalas. Suprimiendo el término «Análisis» se hace justicia con la tradición geográfica al asumir que es la «síntesis» el objetivo final del estudio territorial que incluye análisis-diagnóstico del problema a investigar y reflexión (síntesis) detallada de la realidad actual y futura que se puede presumir del mismo.

Empero, una propuesta más arriesgada, apostaría por la expresión «Geografía Territorial», como denominación del área de conocimiento, entendido el territorio como unidad espacial, sin connotación dimensional alguna, y actuada por el hombre que participa de ciertos rasgos que le otorgan entidad de análisis como ámbito diferenciado. Bajo esta definición se respeta el problema de las escalas de trabajo, aspecto fundamental en el análisis geográfico al no reducir su objeto de estudio al espacio regional. Ya se reiterado la falta de acuerdo unánime en la definición de la región y en la determinación de su tamaño. $\mathrm{Al}$ apostar por la denominación de «Geografía Territorial» se eliminan los problemas de escala de trabajo inherentes a la discutida definición de región y se acepta con toda propiedad al ámbito, dominio, zona, estado, provincia, comarca... como objetos de estudio propios del análisis geográfico. Se trata de una cuestión, de hecho implícita en los estudios llevadas a cabo por los geógrafos regionales que, en sus tareas de investigación han adoptado distintos marcos territoriales como objeto de análisis. Por otra parte, la denominación «Geografía Territorial» se ajusta, en mayor medida, a las nuevas orientaciones «aplicadas» que persigue el reciente proceso de renovación de los planes de estudio de la Licenciatura. Así se señala, en la directriz primera del R.D. 1.447/1990, de 26 de octubre señala que «las enseñanzas conducentes a la obtención del título oficial de Licenciado en Geografía deberán proporcionar una formación científica adecuada en los aspectos básicos y aplicados de la Geografía, el análisis y la ordenación del territorio».

\section{B.5. Propuesta de supresión de las áreas de conocimiento en la Geografía española}

Por encima de propuestas de modificación de denominaciones, por lo que deberíamos apostar como geógrafos es por la fusión de las áreas de conocimiento existentes en una única área de conocimiento: «GEOGRAFÍA».

Proponer la supresión de las áreas de conocimiento es, sin duda, una cuestión cuestión arriesgada y de consenso difícil, pero no por ello, debe ocultarse un sentir más o menos generalizado en el colectivo geográfico de desacuerdo con la actual e irracional división de la disciplina geográfica en tres áreas de conocimiento. No es esta una cuestión exclusivamente nacional, sino que las propuestas de unidad de la geografía está presente por ejemplo en el ámbito anglosajón donde una amplia legión de «iluminados» pensadores geográficos tanto han contribuido, desde los años cincuenta de la presente centuria, a fortalecer la división interna de la disciplina. Así, Tin Unwin, en su brillantísima reflexión sobre la ciencia geográfica ${ }^{5}$, reclama la necesidad urgente de unificar las distintas áreas de conoci-

5 Vid. Unwin, T. (1995): El lugar de la geografía, Ed. Cátedra, Madrid, 342 pp. 
miento geográficas (geografía física y geografía humana, en el mundo anglosajón) para poder afrontar los nuevos temas que se presentan a la investigación geográfica: deterioro ambiental, cambio climático, la gestión de los recursos, la lucha contra la contaminación, etc. Como afirma Unwin, todos estos nuevos temas de contenido medioambiental «requieren un conocimiento sustancial de procesos físicos y prácticas sociales». En suma, se trata de un intento de recuperación de la tradición geográfica que a lo largo de la historia ha demostrado su capacidad para estudiar «la ocupación humana de la tierra».

En nuestro país, la actual división en Áreas de Conocimiento data, como se ha señalado, de principios de los años ochenta con la aprobación de la vigente Ley de Reforma Universitaria, y se ha consolidado en la estructura universitaria española «a efectos de plantilla de profesorado funcionario, creación de Departamentos y constitución de las Comisiones para la resolución de los concursos de dicho profesorado» (López Ontiveros, 1992). Cuestión distinta es preguntarse si su establecimiento ha supuesto un avance en la docencia y la investigación de la disciplina geográfica.

Esta última cuestión merece valoraciones contrapuestas. Para la investigación, la consolidación de las áreas de conocimiento se ha saldado con un aluvión de publicaciones de temática específica que han invadido el panorama editorial de la investigación geográfica. En relación con ello se encuentra, asimismo, la consolidación de grupos específicos dentro de la Asociación de Geógrafos Españoles, la celebración de congresos mono-temáticos y la pérdida de contenidos sufrida por las Reuniones Nacionales. Por su parte, para la docencia, el establecimiento de las áreas de conocimiento ha sido, en mi opinión, funesta. La existencia de rivalidades entre integrantes de distintas áreas de conocimiento se ha trasladado al proceso de gestación de los nuevos planes de estudio, provocando la aparición de situaciones pintorescas como la enseñanza de una misma materia básica para las tres áreas de conocimiento (por ejemplo, teoría y métodos de análisis geográfico regional, teoría y métodos de la geografía física y teoría y métodos de la geografía humana). Se ha perdido la visión integradora de la ciencia geográfica. Cada cual quiere hacer de su asignatura un «reino de taifas» donde nadie pueda inmiscuirse valiéndose para ello de artificios como el empleo de fórmulas matemáticas («signo de cientifismo»), de enfoques supuestamente nuevos, o de recomendaciones bibliográficas interesadas. Se ha llegado a una situación tal en la que el alumno conoce a la perfección cuáles son los efectos de la presencia del $\mathrm{CO}_{2}$ en la troposfera pero desconoce cuál es la capital de un estado africano o asiático o, aún más, cuáles son las comunidades autónomas de España.

Apostar por la fusión de las áreas de conocimiento en una sola GEOGRAFÍA es, en suma, decidir si en el futuro queremos firmar nuestros trabajos y proyectos como climatólogos, geomorfólogos, especialistas en geografía urbana, en turismo, en S.I.G. y teledetección o, simplemente queremos llamarnos GEÓGRAFOS, es decir, conocedores del medio geográfico en todas sus facetas. Con la aparición de áreas de conocimiento y la creciente especialización de las investigaciones hemos decidido construir «murallas chinas» para ir acotando objetos de estudio geográfico que creemos propios e intrasferibles. Lo peor de esta especialización no es el hecho de la especialización en sí sino sus consecuencias, puesto que ello nos aleja de la idea central de la geografía y acabará —en algunos colegas ya lo ha conseguido- haciéndonos renegar de nuestro origen humanista, en aras a un mal entendido cientifismo que supuestamente consiga superar los muchos complejos de inferioridad comunes en nuestra disciplina; complejos que arrancan de una mal conocimiento de las propias bases del pensamiento geográfico y de las posibilidades de estudio que ofrece su objeto de análisis: las relaciones entre el medio y el hombre.

Debemos, pues, aspirar a la unidad de una geografía donde la Geografía Humana — Geografía del Hombre - y la Geografía Física — Geografía del Medio— convergan 
en la explicación de las relaciones existentes entre uno y de la manera diversa en que se presentan esas relaciones en la superficie terrestre.

\section{Reflexión final}

Hacer geografía es preocuparse por interpretar el mundo actual, es indagar sobre las relaciones entre el medio y el hombre y explicar cómo se reparten estas relaciones diversas en la superficie terrestre. Lo demás es elucubrar, calentarse las mientes sin sentido, en suma, hacer lo que no es geografía. Debemos dedicarnos a hacer más geografía y pensar menos en la geografía. Con ello no se defiende la inutilidad del pensamiento geográfico y su necesidad en el devenir de la disciplina, pero, estimo que no deben malgastarse fuerzas innecesariamente centrando la labor investigadora en la reflexión sobre cómo debe hacerse la geografía. La geografía o se hace o no se hace, o se sabe hacer o no se sabe hacer, sin más. Seamos geógrafos porque hagamos GEOGRAFÍA y no porque digamos que pensamos en la geografía. Debemos saber ofrecer visiones territoriales de conjunto que integren todos aquellos aspectos relacionados con una cuestión específica. Es esto lo que más valoran los agentes sociales o los profesionales de temática aneja del geógrafo: su capacidad de síntesis, su reflexión global de los problemas espaciales.

Como señala Unwin (1995), cuando nos pregunten a qué nos dedicamos, «debemos ser capaces de decir con confianza - yo añadiría, con convencimiento- que somos geógrafos; que nos ocupamos de algunas de las cuestiones más vitales que se plantean en la sociedad contemporánea».

Tenemos la difícil tarea de preparar, hoy, los contenidos geográficos que se mostraran a las generaciones del próximo siglo, en definitiva, de elaborar la geografía del mañana, una disciplina científica que muestre al hombre en relación con el medio y la sociedad en la que vive, que presente los problemas e inquietudes que ello supone, otorgándole, en suma, las claves para que pueda mejorar sus condiciones de vida perjudicando lo menos posible su ambiente natural.

Apostemos por la unidad de la ciencia geográfica, por la abolición de las áreas de conocimiento y recuperemos el sentido global de la disciplina. Los nuevos temas que se plantean a la disciplina (medio ambiente, paisaje, cambio climático, contaminación ambiental, nuevo orden mundial) así lo requieren. Recuperemos, como señala Stoddart ${ }^{6}$, la «gran tradición de nuestra disciplina» y consideremos, como en su tiempo lo hacían Forster, Ratzel, Vidal de la Blache o Hettner, que hacemos geografía, una geografía, la geografía.

\section{Bibliografía}

ALBET I MAS, A. (1993): «La nueva Geografía Regional o la construcción social de la región» en Anales de Geografía de la Universidad Complutense, nº 13, Madrid, pp. 11-29.

ARCHER, K. (1993): «Regions as Social Organisms: The Lamarckian Characteristics of Vidal de la Blache's Regional Geography», Annals of the American Geographers, vol. 83, $\mathrm{n}^{\circ}$ 3, september, pp. 498-514.

BENKO, G. y LIPIETZ, A. (edit) (1994): Las regiones que ganan. Nuevos paradigmas de la geografía económica, Edicions Alfons El Magnanim, Generalitat Valenciana, Valencia, $400 \mathrm{p}$.

BINNS, T. (1994): «Geography and education: U.K. perspective» in Progress in Human Geography $n^{\circ}$ 18, 4, Edward Arnold, London, pp. 541-550.

6 Vid. Stoddart, D.R. (1987): «Altas miras para una geografía de final de siglo» en Goméz Méndoza, J. et alt. El pensamiento geográfico, Alianza Editorial, 2a edición, Madrid, pp. 531-545. 
BOSQUE MAUREL, J. y ORTEGA ALBA, F. (1995): Comentario de textos geográficos, Ed. OikosTau, Barcelona, 179 p.

BROSSEAU, M. (1994): «Geography's literature» in Progress in Human Geography n ${ }^{\circ}$ 18, Ed. Edward Arnold, London, pp. 333-353.

BRUNET, R. et DOLLFUS, O. (1990): Mondes Nouveaux, en Geographie Universelle, Ed. Hachette-Reclus, France, 551 p.

CASTILLO REQUENA, J.M. (1993): Análisis geográfico regional y región: entre la tradición geográfica y las tendencias interdisciplinares recientes. Instituto de Estudios Almerienses, Almería, 176 p.

CLAVAL, P. (1993): La Geógraphie au temps de la chute des murs, essais et études, L'Harmattan, París, 343 p.

CLAVAL, P. (1993): «La Geographie, science carrefour» en Acta Geographica, n 96, Societe de Geographie, París, pp. 2-15.

CLAVAL, P. (1995): Initiation a la Geographie regionale, Ed. Nathan Universite, París, 288 p.

COELHO FERREIRA, C. y NEVES SIMOES, N. (1994): A evoluçao do pensamento geográfico, Ed. Gradiva, Lisboa, 142 p.

COLLECTIF RECLUS (1993): «Geographie Universelle et geographie dite regionale»L'Espace Geographique $\mathrm{n}^{\mathrm{o}}$ 3, pp. 255-280.

CONSEJO DE UNIVERSIDADES (1988): Reforma de las enseñanzas universitarias, Licenciado en Geografía, Secretaría General, Ministerio de Educación y Ciencia, Madrid, 163 p.

DE BLIJ, H.J. and MULLER, P.O. (1994): Geography, realms, regions and concepts, Ed. John Wiley \& Co. New York, 591 p. + anexos.

DIRVEN, E., GROENEWEGEN, J. and VAN HOOF, S. (ed.) (1993): Stuck in the region? Changing scales for regional identity, Vereniging Utrechtse Geografie Studenten Vugs, Utrecht, 126 p.

HAVER, J. and HOEKVELD, G. (ed.) (1993): Moving regions, Netherlands geographical studies, Utrecht, $280 \mathrm{p}$.

DOWNS, R. M. (1994): «Being an Becoming a Geographer: An Agenda for Geography Education», Annals of the Association of American Geographers, vol. 84, nº 2, june, pp. 175-191.

DUNCAN, J. (1995): «Landscape Geography», in Progress in Human Geography n 19, 3, Edward Arnold, London, pp. 414-422.

FEYERABEND, P. (1992): Tratado contra el método: Esquema de una teoría anarquista del conocimiento, Ed. Tecnos, Madrid.

GARCÍA FERNÁNDEZ, J. (1978): «La planificación urbana en España» en V Coloquio de Geografía, Universidad de Granada, pp. 419-421.

GARCÍA FERNÁNDEZ, J. (1982): «La Geografía y las otras ciencias» en II Coloquio Ibérico de Geografía, Centro de Estudo Geograficos, Lisboa, pp. 203-218.

GEORGE, P. (1994): Chronique geographique du XXe siecle, París, 129 pp.

GÓMEZ MENDOZA, J., ORTEGA CANTERO, N. (1986): «Geografía y regeneracionismo en España (1875-1936)». Sistema, 77, pp. 77-89.

GÓMEZ MENDOZA, J., MUÑOZ JIMÉNEZ, J., ORTEGA CANTERO, N. (1987): El pensamiento geográfico. ( $2^{\mathrm{a}}$ ed.) Alianza, Madrid. $545 \mathrm{p}$.

GÓMEZ MENDOZA, J. (1986): «Geografías del presente y del pasado. Un itinerario a través de la evolución reciente del pensamiento en Geografía Humana (1970-85)», en Teoría y práctica de la Geografía. Ed. Alhambra. Madrid.

GROSVENOR, G.N. (1995): «In Sight of the Tunnel. the Renaissance of Geography Education» in Annals of the Association of American Geographers, vol. 85 n 3, september, pp. 409-420.

HAGGETT, P. (1987): Geografía: una síntesis moderna. Ed. Omega, Barcelona.

HALE, M. (ed.) (1994): Ecology in Education, London, 207 p.

JOHNSTON, R.J. (1994): Geography and Geographers. Anglo-American Human Geography since 1945, Edward Arnold, London, 361 p.

JOHNSTON, R.J. (1995): «Geographical research, geography and geographers in the changing British university system» in Progress in Human Geography, no 13, 3, Edward Arnold, London, pp. 355-371.

LÓPEZ ONTIVEROS, A. (1992): «La enseñanza de la geografía en la Universidad española» en VV.AA. La Geografía Española (1970-1992), Aportación española al XXVII Congreso de la Unión Geográfica Internacional, Fundación BBV, Madrid, pp. 3-15. 
LÓPEZ PALOMEQUE, F. et alt. (1986): «La enseñanza universitaria de la geografía y el empleo de los geógrafos». Geocrítica, n 64 , Universidad. Barcelona.

MERCIER, G. (1995): «La region et l'Etat selon Friedrich Ratzel et Paul Vidal de la Blache», Annales de Geographie, no 583, mai-juin, Armand Colin, pp. 211-235.

MORENO, A. y MARRON, M.J. (eds.) (1995): Enseñar geografía, de la teoría a la práctica, Ed. Síntesis, Madrid, 397 p.

MURCIA NAVARRO, E. (1995): La Geografía en el sistema de las ciencias. Memoria sobre el concepto, métodos y fuentes y programa de la disciplina, Universidad de Oviedo, Servicio de Publicaciones, $245 \mathrm{p}$.

ORTEGA VALCÁRCEL, J. (1988): «Región y Análisis Regional hoy», en Alternativas de desarrollo regional. XIII Reunión de Estudios Regionales, AECR, Santander, pp. 11-31.

ORTEGA CANTERO, N. (1988): Geografía y cultura, Alianza editorial, Madrid, 121 p.

PUYOL, R. (1995): «Una ciencia del espacio y de las relaciones hombre-medio» en Revista Vela Mayor, año II, n 6, Grupo Anaya, pp. 73 a 79.

STODDART, D. R. (1987): «Altas miras para una geografía de final de siglo» en El pensamiento geográfico (Gómez Mendoza, J. et alt.) Alianza Universidad, Madrid, pp. 531-545.

THRIFT, N. (1990): «For a new regional geography, 1» in Progress in Human Geography, n 14,2 Edward Arnold, London, pp. 272-279.

THRIFT, N. (1991): «For a new regional geography, 2» in Progress in Human Geography, n 15,4 Edward Arnold, London, pp. 456-466.

THRIFT, N. (1993): «For a new regional geography, 3» in Progress in Human Geography n ${ }^{\circ}$ 17, 1, Edward Arnold, London, pp. 92-100.

UNWIN, T. (1995): El lugar de la Geografía, Ed. Cátedra, Madrid, 342 p.

VV. AA. (1994): Encuentros de intercambios de experiencias, Geografía, Historia, Arte y Conocimiento del Medio, Ed. Ecir, SA., Paterna, 471 p.

VV. AA. (1994): La geografía hoy, textos, historia y documentación, Ed. Anthropos, Monografías Temáticas n 43, Barcelona, 191 p.

VV.AA. (1993): «La geografia a l'ensenyament» Documents d'Analisis Geografica, n² 21, (monográfico sobre la enseñanza de la geografía) Publications del Departament de Geografia, Universitat Autónoma de Barcelona.

VV.AA. (1993): Revista Terra, (nº 5 monográfico dedicado a la didáctica de la Geografía), Sociedade Galega de Xeografia, Santiago de Compostela.

ZIMMERER, K.S. (1994): «Human Geography and the «New Ecology»: The Prospect and Promise of Integration», Annals of the Association of American Geographers, vol. 84, $\mathrm{n}^{\circ} 1$, march, pp. 108-125. 